participate in a panel or conference or some other effort and they decline, it's a little off-putting to then ask them, "Can you name some other women?" That's not great for the self-esteem of your female colleagues.

$S G$ : On a larger scale, how do you see the current political climate and movements like MeToo potentially shaping the field?

$F L$ : MeToo presents some really thorny problems for the academy. This is not a legislative studies problem; this is just a problem of how universities are organized. Many wonderful features of universities flow from the tenure system and the independence faculty have. The system allows faculty to work on what they're interested in, not to be subject to the fads that administrators can be very eager to embrace, to develop an expertise because they care about it and believe that it's important, and to keep at it even if maybe not everybody sees the value at any given time-these are great features of the system. The whole decentralized structure of universities, all of that grows out of the tenure system.

If you do away with that, then you introduce new accountability relationships that would have some good features in the form of being able to better police problem behavior. But it would have many downsides for academic freedom and university organization. This is a particularly troubling set of tradeoffs for the MeToo era. Bad faculty behavior is not something universities are great at policing, but growing recognition of this problem highlights that bad faculty behavior is an issue for universities as well as for the victims of inappropriate behavior.

$S G$ : What about citations? Do you cite someone with multiple, credible allegations? Obviously, there's not a right answer to any of this.

$F L$ : That's an interesting question I'd never considered before. My thinking would be that you cite work that influenced you or that was foundational for your work, regardless of the source. If a piece of work was important to the development of your project or your paper, then you cite where citation is due. Personnel decisions are another matter. If you're trying to hire somebody for a job, then you'd absolutely want to take into account whether that person has a record of mistreating students or colleagues. But with regard to citation, that ought to be just on the basis of the academic merits of the matter.

\section{COMMUNITY AS SELF: AN INTERVIEW WITH NADIA E.} BROWN

\section{Guillermo Caballero, Purdue University \\ Jasmine C. Jackson, Purdue University \\ Nadia E. Brown, Purdue University}

\section{DOI: $10.1017 / S_{1049096519002130}$}

An interview between Professor Nadia E. Brown and her graduate students, Guillermo Caballero and Jasmine C. Jackson, was conducted on November 3, 2018, at the request of the editors of The Legislative Scholar. Given the small numbers of women in the Legislative Studies Section (LSS), the newsletter editors were interested in learning more about their experiences in the legislative studies subfield. Caballero and Jackson used the basis of the editors' questions to guide the interview and added two more questions focused on the intersection of gender and race.
The following discussion summarizes their conversation with Professor Brown.

1. What were your initial motivations to study Black women lawmakers? Furthermore, has your motivation to continue to study Black women changed since then?

I went to Howard University for undergrad, a historically Black college and university. At Howard, it was Black politics all the time, which was a wonderful introduction to the field and provided a solid foundation of what Black politics was. But there was little scholarly attention to gender. When I went to Rutgers University for my $\mathrm{PhD}$, my major field was women in politics. Although concentrating on gender politics was really illuminating, it was all about white women. What stuck out to me was the limited amount of scholarship on Black women, both at the level of political elites and mass citizenship. Thus, for me, it was an obvious place to conduct research. From my own lived experiences of seeing Black women champion inclusive politics and policy, I knew that Black women had a distinct voice. However, this voice was often in the shadows and was not being recognized in the scholarship. Both experiences taught me that the problem was deeper than just "no one has done this before" and that there were qualitative differences that needed to be explored.

2. Has the field changed since you started as an assistant professor? If so, how?

I think it has changed; I am really excited and enthusiastic about the next generation of scholars who do solid racial, ethnic, and gender politics. I used to be one of only a handful of scholars that did this kind of work. Now I can point to a whole cohort of scholars who do women of color studies. Sarah Allen Gershon and I published an edited volume on minority women's politics (Brown and Gershon 2016). This captures the types of research that I would never have had the opportunity to read or to think about when I was a graduate student or assistant professor, in large part because there were too few scholars that did this kind of research. Now, the field is growing.

Following this conversation, Caballero and Jackson explored how prevalent this type of intersectional research has been in the legislative studies field. Demographic information on the authors, as well as the subject of publications in issues 42 and 43 of the Legislative Studies Quarterly, suggests that this research is not well represented in this journal. No Black scholars of any gender identification were published in these issues. There were three scholars of Asian descent (two women and one male), seven Latinx scholars (five male and two Latinas), and two nonwhite scholars (one male and one female). Moreover, we found that the majority of scholars published in these issues were white men (71) and that the second most-published group was white women (15). In terms of the subject of the manuscripts that were published in these two issues, only two studies mentioned race and ethnicity, one mentioned same-sex marriage, and four mentioned women. These patterns suggest that even if research in this area is growing, it still may be confined to journals that focus on gender and race.

3. How was your experience trying to become a part of a field dominated by white male scholars? Was it easy? Difficult? Why? 
I took a route that insulated myself from the gender and racial patterns in the field. I went to supportive spaces like the Race, Ethnicity, and Politics Section or the Women and Politics Section. There are people in these sections that obviously do work on representation and legislative studies. I was looking for an intellectual community that studied women of color and that did intersectional work, but I was also looking for support. I was looking for friendly faces. I was looking for people who could be that auntie figure, or that cheerleader, or that supportive kind of fictive kin throughout the discipline. That did not lead me to LSS business meetings or caucuses. I was intentionally looking for spaces to get both academic and personal affirmation.

4. In your view, what are the disadvantages women face for being part of a predominantly white male field? Do you think that these disadvantages are the same, different, or parallel as compared to women scholars who have other intersecting identities? For example, women of color, queer women, and trans women.

One of the challenges facing a scholar doing work on intersectional identities in this field is that I am often asked how is my research universal or how can you generalize from doing
We all need to have these kinds of guides, these mentors that can help you develop. There are also a whole host of other scholars that make up my community and are important to have. Doing good scholarship is a community activity, and that means you have to be vulnerable and you have to be willing to seek community. But that also means you have to be a good community member yourself. So, it is reciprocal; you need to show up and be part of a community.

6. Is there anything you thought of when you were speaking that you wanted to say before we end our meeting? Or anything that comes to the forefront after having this conversation and thinking about your experience as a scholar?

I am pleasantly surprised for the invitation from LSS and I am energized by their awareness to do something to reach out to feminist scholars and women academics in particular. But I am also thinking about those that were not asked and those that are not here to tell their own stories. In my particular instance, I am thinking about other women of color. Were Native women asked? What are Latinas sharing? Queer scholars? How are Asian American women or first-gen women responding to these kinds of questions? It is not enough to be the token woman of color; you have to do something to make

\section{Doing good scholarship is a community activity, and that means you have to be vulnerable and you have to be willing to seek community.}

research on Black women? While these questions may have good analytical points, they can also be seen as gatekeeping questions because other scholars who do work that is posited to be identity free do not get asked those kinds of questions. Scholars who do not work on marginalized groups do not get as many questions about whether the research is generalizable or broad enough or has applications outside of one particular setting. It is also my impression that doing this narrow kind of identity politics work does not get you published in top journals-something I think I have internalized, unfortunately. So, that is a barrier. I would say this is universal for research on other intersecting identities too, not just Black women.

5. What strategies might be beneficial for the next generation of women scholars? In your experience, what strategies have helped you in the different stages of your academic journey?

Good mentorship matters, and I have been extremely fortunate to have two really exemplary mentors from my graduate-school days. Jane Junn and Alvin Tillery have consistently listened to me and helped me figure out the next best move for me. They give me advice based on what is best for me as a person, not just as a scholar. Jane and $\mathrm{Al}$ are a constant source of encouragement when I had (have) imposter syndrome. They give tough love when I am thinking about doing something outlandish. For the next generation, I think it is really important that young scholars know that they cannot do it on their own. space for others and really expand the table. There should be some stuff for you at the table but also for everyone. So, I am grateful to LSS for offering this opportunity for me to be in the $P S$ spotlight. But I also want to highlight the gaps in the margins. What other constituencies are underrepresented? We need to include their scholarship and their voices.

\section{REFERENCE}

Brown, Nadia E., and Sarah Allen Gershon. 2016. Distinct Identities: Minority Women in US Politics. Abingdon-on-Thames, England: Routledge.

\section{WHERE DO WE GO FROM HERE?}

Tracy Sulkin, University of Illinois at Urbana-Champaign

\section{DOI: $10.1017 / S_{1049096519002142}$}

I consider it one of the great fortunes of my professional life to have stumbled upon the legislative studies community. I did not enter graduate school planning to study Congress. Instead, I knew I was interested in quantitative approaches and had some nascent interests in political behavior. In fact, I did not really leave graduate school thinking of myself as a legislative studies scholar (at least not wholly). My dissertation-which later became my first book, Issue Politics in Congress (Sulkin 2005) was motivated by a focus on agendas as a linkage between campaigns and governing and by a developing interest in representation and responsiveness. (On the job market, I applied 